\title{
A new and facile synthetic approach to substituted 2-thioxoquinazolin-4-ones by the annulation of a pyrimidine derivative
}

\author{
Nimalini D. Moirangthem and Warjeet S. Laitonjam*
}

\author{
Full Research Paper \\ Address: \\ Department of Chemistry, Manipur University, Canchipur 795003 , \\ Manipur, India \\ Email: \\ Nimalini D. Moirangthem - nima_moirangthem@rediffmail.com; \\ Warjeet S. Laitonjam* - warjeet@yahoo.com \\ * Corresponding author \\ Keywords: \\ benzenoid; ethylcyanoacetate; malononitrile; pyrimidine; \\ 2-thioxoquinazolin-4-ones
}

\author{
Beilstein J. Org. Chem. 2010, 6, 1056-1060. \\ doi:10.3762/bjoc. 6.120 \\ Received: 18 August 2010 \\ Accepted: 21 October 2010 \\ Published: 09 November 2010 \\ Associate Editor: I. Marek \\ (c) 2010 Moirangthem and Laitonjam; licensee Beilstein-Institut. \\ License and terms: see end of document.
}

\begin{abstract}
A new and facile synthesis of 2-thioxoquinazolin-4-ones by introducing a benzenoid system in the pyrimidine moiety by reacting ethoxymethylene derivatives of 1,3-diarylthiobarbituric acids (DTBA) with active methylene compounds, such as malononitrile and ethyl cyanoacetate, in presence of $\mathrm{ZnCl}_{2}$ has been developed.
\end{abstract}

\section{Introduction}

Quinazolines and derivatives are of much interest due to their biological activities [1,2]. Additionally, quinazolines are interesting targets for new method development due to their importance in numerous therapeutic areas. Recently, antitumor [3] and anti-HIV activities [4,5] of quinazolines have been described. A large number of quinazoline derivatives, which contain the 4-oxo-2-thioxo-1,2,3,4-tetrahydropyrimidine structural moiety in their heterocyclic rings, possess a wide range of biological activities [6-8]. There are a number of synthetic methods available for the preparation of quinazolines [9]. The most common synthetic route involves the amidation of 2-aminobenzoic acid or its derivatives, i.e., 2-aminobenzonitrile, 2-aminobenzoates, and 2-arylnitrilium salts, followed by oxidative ring closure [10-13]. Other synthetic pathways include the cyclization of anthranilamides with aldehydes [14], and with ketones or acid chlorides under acidic or basic conditions [15-17]. However, most of the methods involve multistep processes and time-consuming experimental procedures, and give poor yields or use toxic reagents. Moreover, very few methods are reported for the synthesis of 2-thioxoquinazolin-4ones, as most of the methods reported are for quinazolin2,4(1H,3H)-diones. Recently, Saeed et al. [18] reported the base catalyzed intramolecular nucleophilic cyclization of substituted thioureas in the presence of DMF to afford 2-thioxoquinazolin4-ones. The preparation of 2-thioxoquinazolin-4-one libraries by solid-phase synthesis has been reported [19-21]. 
There are two approaches for the solution-phase parallel synthesis of 2-thioxoquinazolin-4-ones [22]. The first approach is based on the reaction of methyl anthranilates with isothiocyanates in refluxing pyridine or DMF. The second approach involves briefly heating 2-(methylcarboxy)-benzeneisothiocyanates in isopropyl alcohol with a wide variety of primary aliphatic or aromatic amines and their derivatives. Thus, most of the methods for the preparation of such compounds start with the benzene ring in place followed by construction of the pyrimidine ring. We have developed a new facile and convenient synthetic approach to 2-thioxoquinazolin-4-ones by constructing the benzene ring onto an existing pyrimidine moiety.

As a part of our synthetic strategy, 1,3-diarylthiobarbituric acids (DTBA) were used as precursors for the synthesis of various fused heterocyclic compounds. In recent years, we have reported one-pot cyclizations of DTBA with hydrazine [23,24], hydroxylamine [25], guanidine [26], etc. In addition, one-pot cyclizations of DTBA-derived arylidenes have also been reported. Recently, we reported the synthesis of fused heterocycles from ethoxymethylene derivatives of DTBA [27]. In continuation of our work on the synthesis of fused heterocycles $[28,29]$, we herein report full details of the work and studies related to the synthesis of 2-thioxoquinazolin-4-ones from the reaction of ethoxymethylene derivatives of DTBA and active methylene compounds, such as, malononitrile and ethylcyanoacetate.

\section{Results and Discussion}

DTBA are among the simplest synthetic intermediates and can be easily prepared in a one-pot reaction by treating 1,3-diaryl thioureas with malonic acid in the presence of acetyl chloride. DTBA undergoes condensation with ethyl orthoformate to give the condensation products, 5-ethoxymethylene-1,3-diaryl-2thiobarbituric acids $\mathbf{1}$. These condensation products possess three electrophilic centers and can undergo cyclocondensation with various nucleophiles to give a number of fused heterocyclic systems that contain a pyrimidine ring. Thus, treatment of 1 with malononitrile in presence of $\mathrm{NH}_{4} \mathrm{OAc}$ with $\mathrm{ZnCl}_{2}$ as catalyst in refluxing acetic acid gives the corresponding 2-thioxoquinazolin-4-ones 2 in $78-85 \%$ overall yields (Scheme 1).

During the optimization of the cyclization of ethoxymethylene derivatives of DTBA with malononitrile, the choice of the base proved to be an important parameter. The use of $\mathrm{NEt}_{3}$ (TEA) or piperidine (in DCM or ethanol) resulted in the formation of complex mixtures (Table 1, entries 1-4). Screening at different temperatures demonstrates that some of the catalysts failed to react at room temperature (rt) and also even after heating under

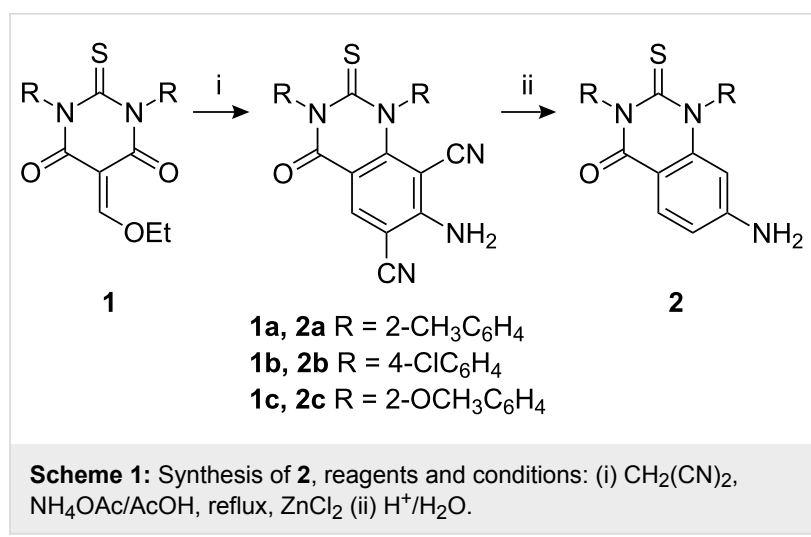

reflux (Table 1, entries 5-8). The reaction failed with both $\mathrm{ZnCl}_{2}$ and $\mathrm{FeCl}_{3}$ in $\mathrm{MeOH}$ solution at rt. Similarly, no reaction was observed with $\mathrm{NaOCH}_{3}$ and $\mathrm{MeOH}$ at rt. On the other hand, with $\mathrm{NaOCH}_{3}$ as base in $\mathrm{MeOH}$ and $\mathrm{ZnCl}_{2}$ as catalyst at rt, a relatively low yield of $\mathbf{2 a}$ was obtained (Table 1, entry 9). However, when this reaction was repeated in refluxing solvent the yield was increased.

\begin{tabular}{|c|c|c|}
\hline Entry & Conditions & Yield $(\%)$ \\
\hline 1 & $\mathrm{NEt}_{3}$ in DCM & no product \\
\hline 2 & $\mathrm{NEt}_{3}$ in $\mathrm{EtOH}$ & no product \\
\hline 3 & piperidine in DCM & no product \\
\hline 4 & piperidine in $\mathrm{EtOH}$ & no product \\
\hline 5 & $\mathrm{ZnCl}_{2}$ in $\mathrm{MeOH}^{\mathrm{a}, \mathrm{b}}$ & no product \\
\hline 6 & $\mathrm{FeCl}_{3}$ in $\mathrm{MeOH}^{\mathrm{a}, \mathrm{b}}$ & no product \\
\hline 7 & $\mathrm{AlCl}_{3}$ in $\mathrm{MeOH}^{\mathrm{a}, \mathrm{b}}$ & no product \\
\hline 8 & $\mathrm{NaOCH}_{3}$ in $\mathrm{MeOH}^{\mathrm{a}}$ & no product \\
\hline 9 & $\mathrm{NaOCH}_{3}$ in $\mathrm{MeOH}^{\mathrm{b}}$ & 24 \\
\hline 10 & $\mathrm{NaOCH}_{3}$ in $\mathrm{MeOH}, \mathrm{ZnCl}_{2}^{\mathrm{b}}$ & 35 \\
\hline 11 & $\mathrm{NH}_{4} \mathrm{OAc}$ in $\mathrm{AcOH}^{\mathrm{b}}$ & 67 \\
\hline 12 & $\mathrm{NH}_{4} \mathrm{OAc}$ in $\mathrm{AcOH}^{\mathrm{b}}$ & 85 \\
\hline
\end{tabular}

${ }^{a}$ Reactions were carried out at room temperature. ${ }^{b}$ Reactions were carried out at reflux. CIsolated yield.

In contrast, the use of $\mathrm{NH}_{4} \mathrm{OAc}$ in refluxing acetic acid resulted in a clean cyclization to give the desired product. Dehydration and decarboxylation induced by the higher temperature and the acid produces the required quinazoline. To obtain the optimal conditions, a variety of catalysts were also investigated to detect the catalytic activities of different metal ions and acetate in the production of 2a (Table 2). It was found that $\mathrm{NH}_{4} \mathrm{OAc} / \mathrm{AcOH}$ in $\mathrm{ZnCl}_{2}$ was the most effective (Table 2, entries 1 and 7-13); $\mathrm{CuCl}_{2}$ and $\mathrm{HgCl}_{2}$ also promoted the reactions, but the yields were poor, $22 \%$ and $12 \%$, respectively (Table 2, entries 2 and 3). Other catalysts, including $\mathrm{FeCl}_{3}, \mathrm{AlCl}_{3}$ etc. failed to afford any $\mathbf{2 a}$ (Table 2, entries 4-6). We further found that the best 
yield of 2 a was obtained when 5 equiv of $\mathrm{ZnCl}_{2}$ was used (Table 2, entry 13). The excessive amount of $\mathrm{ZnCl}_{2}$ for the annulation is probably due to the chelating effect of zinc ion. Thus, the $\mathrm{NH}_{4} \mathrm{OAc} / \mathrm{AcOH}$ combination in $\mathrm{ZnCl}_{2}$ was found to be the best and gave the highest yield of $\mathbf{2 b}(85 \%)$ after refluxing for $6 \mathrm{~h}$.

\begin{tabular}{|c|c|c|}
\hline Entry & Conditions & Yield $^{\mathrm{b}}(\%)$ \\
\hline 1 & 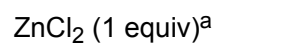 & 30 \\
\hline 2 & $\mathrm{CuCl}_{2}(1 \text { equiv })^{\mathrm{a}}$ & 22 \\
\hline 3 & $\mathrm{HgCl}_{2}(1 \text { equiv })^{\mathrm{a}}$ & 12 \\
\hline 4 & $\mathrm{FeCl}_{3}(1 \text { equiv })^{\mathrm{a}}$ & 0 \\
\hline 5 & $\mathrm{AlCl}_{3}(1 \text { equiv })^{\mathrm{a}}$ & 0 \\
\hline 6 & $\mathrm{SnCl}_{2}(1 \text { equiv })^{\mathrm{a}}$ & 0 \\
\hline 7 & $\mathrm{ZnCl}_{2}(0.5 \text { equiv })^{\mathrm{a}}$ & 18 \\
\hline 8 & $\mathrm{ZnCl}_{2}(2 \text { equiv })^{\mathrm{a}}$ & 45 \\
\hline 9 & $\mathrm{ZnCl}_{2}(5 \text { equiv, } 2 \mathrm{~h})^{\mathrm{a}}$ & 62 \\
\hline 10 & $\mathrm{ZnCl}_{2}$ (5 equiv, rt, $4 \mathrm{~h}$ ) & 28 \\
\hline 11 & $\mathrm{ZnCl}_{2}$ (5 equiv, rt, $6 \mathrm{~h}$ ) & 38 \\
\hline 12 & $\mathrm{ZnCl}_{2}(5 \text { equiv, } 4 \mathrm{~h})^{\mathrm{a}}$ & 74 \\
\hline 13 & $\mathrm{ZnCl}_{2}(5 \text { equiv, } 6 \mathrm{~h})^{\mathrm{a}}$ & 85 \\
\hline
\end{tabular}

a Reactions were carried out with $\mathrm{NH}_{4} \mathrm{OAc}$ and $\mathrm{AcOH}$ at reflux. $\mathrm{b}$ Isolated yield.

After optimizing the conditions, various DTBAs were used to react with malononitrile and the results are listed in Table 3. On the basis of the above noted results, a possible reaction mechanism is shown in Scheme 2. The reaction of the 5-ethoxymethylene-1,3-diaryl-2-thiobarbituric acids with malononitrile gave intermediate $\mathbf{A}$, which undergoes intramolecular cyclization to form the intermediate $\mathbf{B}$, and then acid hydrolysis of $\mathbf{B}$ afforded 2. Further evidence is that the reaction of 5-ethoxymethylene1,3-diaryl-2-thiobarbituric acids with malononitrile under the standard conditions. This reaction only gave quinazolines and no other products were detected. In addition, this proposed mechanism was also confirmed from the literature [30,31].

Table 3: Synthesis of 7-amino-2,3-dihydro-2-thioxo-1,3-diarylquinazolin-4(1H)-ones ${ }^{\text {. }}$.

\begin{tabular}{lll} 
Product & $\mathrm{R}$ & Yield (\%) \\
\hline 2a & $2-\mathrm{CH}_{3} \mathrm{C}_{6} \mathrm{H}_{4}$ & 83 \\
$\mathbf{2 b}$ & $4-\mathrm{ClC}_{6} \mathrm{H}_{4}$ & 85 \\
2c & $2-\mathrm{OCH}_{3} \mathrm{C}_{6} \mathrm{H}_{4}$ & 78 \\
\hline
\end{tabular}

aReactions were carried out with $\mathrm{NH}_{4} \mathrm{OAc}$ and $\mathrm{AcOH}$ at reflux. bIsolated yield.

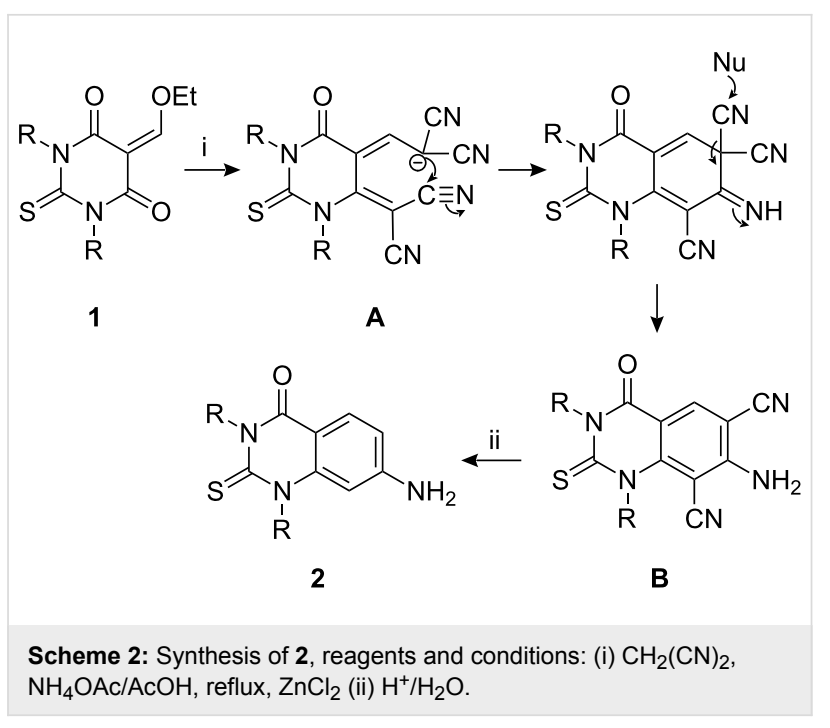

The reaction of 5-ethoxymethylene-1,3-diaryl-2-thiobarbituric acids 1 with ethylcyanoacetate in presence of ammonium acetate and acetic acid with $\mathrm{ZnCl}_{2}$ as a catalyst afforded 7-hydroxy-2,3-dihydro-2-thioxo-1,3-diarylquinazolin-4(1H)ones 3 in $76-87 \%$ overall yields (Scheme 3) [32,33] and these results are listed in Table 4.

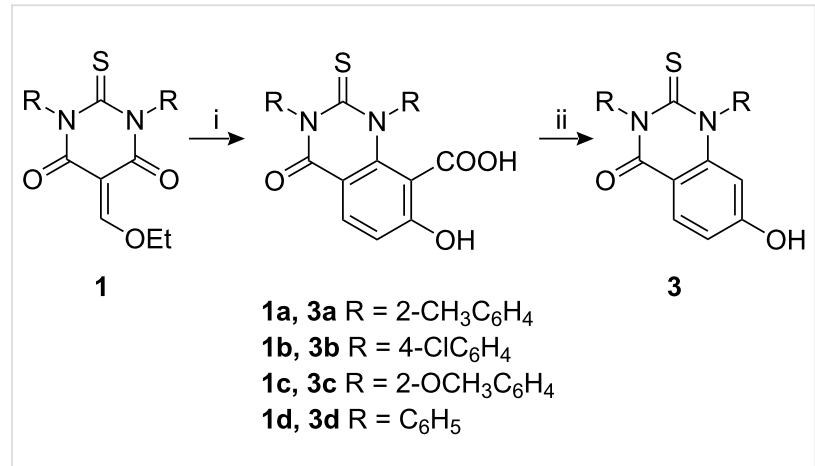

Scheme 3: Synthesis of 3, reagents and conditions: (i) $\mathrm{NC}-\mathrm{CH}_{2-}$ $\mathrm{CO}_{2} \mathrm{Et}, \mathrm{NH}_{4} \mathrm{OAc} / \mathrm{AcOH}$, reflux, $\mathrm{ZnCl}_{2}$ (ii) $\mathrm{H}_{3} \mathrm{O}^{+}$.

$\begin{aligned} & \text { Table 4: Synthesis of 7-hydroxy-2,3-dihydro-2-thioxo-1,3-diarylquina- } \\
& \text { zolin-4(1H)-ones }\end{aligned}$.
\begin{tabular}{lll} 
Product & $\mathrm{R}$ & Yield (\%) \\
\hline 3a & $2-\mathrm{CH}_{3} \mathrm{C}_{6} \mathrm{H}_{4}$ & 82 \\
3b & $4-\mathrm{ClC}_{6} \mathrm{H}_{4}$ & 87 \\
3c & $2-\mathrm{OCH}_{3} \mathrm{C}_{6} \mathrm{H}_{4}$ & 80 \\
3d & $\mathrm{C}_{6} \mathrm{H}_{5}$ & 76 \\
\hline
\end{tabular}

aReactions were carried out with $\mathrm{NH}_{4} \mathrm{OAc}$ and $\mathrm{AcOH}$ at reflux. b/solated yield. 


\section{Conclusion}

The cyclocondensation of ethoxymethylene thiobarbituric acids with active methylene compounds under the above noted catalytic system, resulted in a new method for the formation of quinazoline derivatives. Thus, the reaction of 5-ethoxymethylenepyrimidine-4,6-diones 1 with malononitrile and ethyl cyanoacetate gave 7-amino-2,3-dihydro-2-thioxo-1,3-diarylquinazolin-4(1H)-ones 2 and 7-hydroxy-2,3-dihydro-2-thioxo-1,3diarylquinozolin-4(1H)-ones $\mathbf{3}$, respectively. This new procedure avoids the use of toxic reagents which are traditionally used for the preparation of quinazolines.

\section{Supporting Information}

\section{Supporting Information File 1}

Experimental part.

[http://www.beilstein-journals.org/bjoc/content/

supplementary/1860-5397-6-120-S1.pdf]

\section{Supporting Information File 2}

IR and NMR spectra.

Supporting Information feature copies of IR and ${ }^{1} \mathrm{H}$ NMR spectra of

7-amino-2,3-dihydro-2-thioxo-1,3-di(2-methoxyphenyl)quinazolin-4(1H)-one (2c) and ${ }^{1} \mathrm{H}$ and ${ }^{13} \mathrm{C}$ NMR spectra of 7-hydroxy-2,3-dihydro-2-thioxo-1,3-di(2-methylphenyl)quinazolin-4(1H)-one (3a).

[http://www.beilstein-journals.org/bjoc/content/ supplementary/1860-5397-6-120-S2.pdf]

\section{Acknowledgements}

The authors thank SAIF, NEHU, Shillong for taking NMR spectral data.

\section{References}

1. Connolly, D. J.; Cusack, D.; O'Sullivian, T. P.; Guiry, P. J. Tetrahedron 2005, 61, 10153-10202. doi:10.1016/j.tet.2005.07.010

2. Mhaske, S. B.; Argade, N. P. Tetrahedron 2006, 62, 9787-9826. doi:10.1016/j.tet.2006.07.098

3. Xia, Y.; Yang, Z.-Y.; Hour, M.-J.; Kuo, S.-C.; Xia, P.; Bastow, K. F.; Nakanishi, Y.; Nampoothiri, P.; Hackl, T.; Hamel, E.; Lee, K.-H. Bioorg. Med. Chem. Lett. 2001, 11, 1193-1196. doi:10.1016/S0960-894X(01)00190-1

4. De Clercq, E. Curr. Med. Chem. 2001, 8, 1543-1572.

5. Corbett, J. W. Curr. Med. Chem. - Anti-Infect. Agents 2002, 1 , $119-140$

6. LeMahieu, R. A.; Carson, M.; Welton, A. F.; Baruth, H. W.; Yaremko, B. J. Med. Chem. 1983, 26, 107-110. doi:10.1021/jm00355a022

7. Vandenberk, J.; Kennis, L.; Van der Aa, M.; Van Heertum, A. U.S. Patent 4, 522, 945, June 11, 1985.

8. Sohda, T.; Makino, H.; Baba, A. Eur. Patent EP0567107, Oct 27, 1993.
9. Jiarong, L.; Xian, C.; Daxin, S.; Shuling, M.; Qing, L.; Qi, Z.; Jianhong, T. Org. Lett. 2009, 11, 1193-1196. doi:10.1021/ol900093h

10. Li, Z.; Huang, H.; Sun, H.; Jiang, H.; Liu, H. J. Comb. Chem. 2008, 10, 484-486. doi:10.1021/cc800040z

11. Patil, Y. P.; Tambade, P. J.; Parghi, K. D.; Jayaram, R. V.; Bhanage, B. M. Catal. Lett 2009, 133, 201-208. doi:10.1007/s10562-009-0126-5

12. Couture, A.; Cornet, H.; Grandclaudon, P. Synthesis 1991, 1009-1010. doi:10.1055/s-1991-26632

13. Kotsuki, H.; Sakai, H.; Morimoto, H.; Suenaga, H. Synlett 1999, 1993-1995. doi:10.1055/s-1999-2998

14. Abdel-Jalil, R. L.; Voelter, W.; Saeed, M. Tetrahedron Lett. 2004, 45, 3475-3476. doi:10.1016/j.tetlet.2004.03.003

15. Feldman, J. R.; Wagner, E. C. J. Org. Chem. 1942, 7, 31-47. doi:10.1021/jo01195a006

16. Yale, H. L. J. Heterocycl. Chem. 1977, 14, 1357-1359. doi:10.1002/jhet.5570140812

17. Mhaske, S. B.; Argade, N. P. J. Org. Chem. 2004, 69, 4563-4566. doi:10.1021/jo040153v

18. Saeed, A.; Shaheen, U.; Bolte, M. J. Chin. Chem. Soc. 2010, 57, 82-88.

19. Makino, S.; Suzuki, N.; Nakanishi, E.; Tsuji, T. Tetrahedron Lett. 2000, 41, 8333-8337. doi:10.1016/S0040-4039(00)01442-8

20. Makino, S.; Nakanishi, E.; Tsuji, T. Tetrahedron Lett. 2001, 42, 1749-1752. doi:10.1016/S0040-4039(01)00008-9

21. Makino, S.; Nakanishi, E.; Tsuji, T. Bull. Korean Chem. Soc. 2003, 24, 389-392. doi:10.5012/bkcs.2003.24.3.389

22. Ivachtchenko, A. V.; Kovalenko, S. M.; Drushlyak, O. G. J. Comb. Chem. 2003, 5, 775-788. doi:10.1021/cc020097g

23. Devi, N. A.; Laitonjam, W. S. Indian J. Chem. 1994, 33B, 1091-1092.

24. Devi, N. A.; Laitonjam, W. S. Indian J. Heterocycl. Chem. 1995, 5, 139-140.

25. Devi, N. A.; Laitonjam, W. S. Indian J. Chem. 1996, 35B, 478-479.

26. Devi, N. A.; Khuman, C. K.; Singh, R. K. T.; Laitonjam, W. S. Indian J. Heterocycl. Chem. 1998, 7, 193-196.

27. Thokchom, H. S.; Devi, N. A.; Laitonjam, W. S. Can. J. Chem. 2005, 83, 1056-1062. doi:10.1139/v05-054

28. Laitonjam, W. S.; Rajkumar, T. S.; Chingakham, B. S. Steroids 2002 , 67, 203-209. doi:10.1016/S0039-128X(01)00146-5

29. Tombisana, R. K.; Laitonjam, W. S. Indian J. Chem. 1999, 38B, 847-849.

30. Green, B.; Khaidem, I. S.; Crane, R. I.; Newaz, S. S. Tetrahedron 1976, 32, 2997-3001. doi:10.1016/0040-4020(76)80158-5

31. Khaidem, I. S.; Sagolsem, L. S.; Laishram, R. S.; Khan, M. Z. R. Indian J. Chem. 1996, 35B, 911-914.

32. Ghosh, A. K.; Bilcer, G.; Schiltz, G. Synthesis 2001, 2203-2229. doi:10.1055/s-2001-18434

33. List, B.; Castello, C. Synlett 2001, 1687-1689. doi:10.1055/s-2001-18095 


\section{License and Terms}

This is an Open Access article under the terms of the Creative Commons Attribution License

(http://creativecommons.org/licenses/by/2.0), which permits unrestricted use, distribution, and reproduction in any medium, provided the original work is properly cited.

The license is subject to the Beilstein Journal of Organic Chemistry terms and conditions:

(http://www.beilstein-journals.org/bjoc)

The definitive version of this article is the electronic one which can be found at:

doi:10.3762/bjoc. 6.120 